University of the Pacific

Scholarly Commons

McGeorge School of Law Other Faculty Works McGeorge School of Law Faculty Scholarship

2009

\title{
Find Them on Facebook: Using Facebook to Reach Students Where They Already Go
}

Courtney G. Lee

Pacifc McGeorge School of Law

Follow this and additional works at: https://scholarlycommons.pacific.edu/facultyother

Part of the Legal Education Commons

\section{Recommended Citation}

Courtney G. Lee, Find Them on Facebook: Using Facebook to Reach Students Where They Already Go, The Learning Curve, Fall 2009, at 21.

This Article is brought to you for free and open access by the McGeorge School of Law Faculty Scholarship at Scholarly Commons. It has been accepted for inclusion in McGeorge School of Law Other Faculty Works by an authorized administrator of Scholarly Commons. For more information, please contact mgibney@pacific.edu. 


\section{FIND THEM ON FACEBOOK: USING FACEBOOK TO REACH STUDENTS Where They AlReAdy Go}

\section{Courtney G. Lee}

Director of Academic Success \& Lecturer in Law, University of the Pacific, McGeorge School of Law

In the digital age, it is increasingly difficult to connect with students. It's ironic, if you think about it; the more methods of communication that are available, the more difficult it becomes to find one that reaches everyone. Many schools have an extremely difficult time convincing their students to check their school e-mail accounts, and the students who do check them often admit to deleting many messages without reading them, or only checking in sporadically. Furthermore, the students who do check their school e-mail accounts are not the same students who read posted flyers, and those are not the same students who check their school's YouTube channel, podcasts, "snail-mail," etc. It can quickly become a huge drain of time and resources to cover every possible base, particularly if you are the only person in your department.

I have faced this dilemma many times. Few things are more frustrating than pouring time, effort, and money into orchestrating and advertising a program, only to hear months later from students who say, "That sounds like it was great! I wish I had known about it!" Exasperated, I asked myself how I could reach the students where they already go, instead of trying to push them to respond to my chosen medium. The answer was clear: use Facebook. Today's students not only check Facebook - they check it voluntarily, and they check it often. Stroll past a room on campus with wireless capabilities sometime, and you'll probably see a lot of laptop screens with that familiar blue Facebook homepage banner across the top.

So how does it work, and how can you use it to reach your own students? Fortunately, it's extremely easy. First, if you do not already have an individual profile, visit www.facebook.com and sign up. Your profile can be as detailed or as vague as you'd like; you can share your location, job, personal information, photos, videos, and links, or you can just share your name and leave everything else blank. If you already have a profile but you don't relish the idea of sharing every aspect of your personal life with your students, you might want to consider setting up a separate, "professional" profile.

Once you have a profile, the next step is to set up a Facebook group, which is an online gathering place for like-minded individuals on Facebook. Facebook groups exist by the thousands, and there is a group for almost everything and everyone: rock bands, television shows, class reunions, cities, memorials, etc. (There is even a group for people who love beef jerky.) The legal field already has a strong presence on Facebook; for example, if you type the words "law
"The more methods of communication

that are available, the more difficult it becomes to find one that reaches everyone." 
PAGE 22

"Even the most

skeptical student is

likely to join a group

when he or she sees

that five or six

friends have joined. “

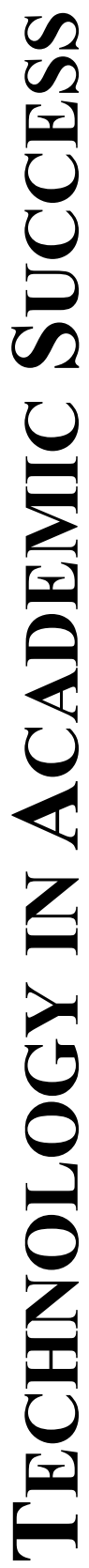

group" in the search field, you will find thirty thousand results.

Before setting up a group, you must determine your audience. Do you want to reach the entire student body, or select segments? I prefer to keep my current students and my alumni bar takers separate because they have such different needs. You might even want to create separate groups for each class year. Remember the students who admitted to deleting school e-mail messages without reading them? Students will similarly lose interest if they join your Facebook group only to see that much of the content does not apply specifically to them. Their time is probably more precious to them now than ever before, and if your group seems to waste it, they will stop caring.

Once you have established your target audience, you can choose a name and set up your group page. Just click on the "groups" icon at the bottom of the screen, which looks like the silhouettes of two heads, and then click the button at the top of the page that says "+ Create a New Group." The directions will lead you through the rest. Upload a picture to identify your group, whether it's your own photo or your school logo, and then you can start searching for students and inviting them to join.

Once a few students join, it should spread like wildfire, because each time one person joins the group, a message appears on that person's friends' homepages saying that he or she joined. Even the most skeptical student is likely to join a group when he or she sees that five or six friends have joined. When I set up my bar prep group last summer, a steady stream of new members joined at a rate of about ten to fifteen per week.

More people may have regularly viewed my group page than have formally joined as members, however. When establishing your group, you may choose from varying degrees of privacy control: open, closed, and secret. Open groups are completely available to any and all members of Facebook, whether they join the group as members or not. Closed groups force potential members to submit requests to the group administrators before they may join, and until those requests are approved, they can only see the group's description. Membership to secret groups is by invitation only, and no outside members of the Facebook public see any information about the group. I chose the open option for my groups because I was more concerned with information dissemination rather than statistics, but a closed group might better serve the needs of a department seeking an accurate count of how many students have accessed the group page in its entirety.

Regardless of how you keep track of your audience, once you have one, you must keep its attention. Try to have a plan of what you want to share, and spread things out to ensure that your students don't get overwhelmed by too much information at once. Furthermore, if you post everything immediately, you may not have any content to share for a few weeks, and the students may stop checking the page. The good news is that the information you can share through your Facebook group is practically endless: you can post links, short comments, long discussion topics, photos, videos, and events. It's easy to find something new to share each week.

A particularly nice feature of Facebook groups is the "Create Group Event" option. I used it with great success to promote practice exams, but it can just as easily be used for makeup classes, social gatherings, guest lectures, etc. Once you create your event on your group page, you may invite all or some 
of the group members to attend. A link to the event invitation will then appear on each invited member's Facebook homepage. If the student accepts the invitation, a message will then appear on that student's friends' pages stating that the student plans to attend the event, and the domino effect begins.

Facebook practically does the marketing for you.

Even if these capabilities do not sound exciting, Facebook might prove useful to your program simply by paving an extra avenue of support to your students. Surrounded by pictures and notes from friends and family, students might feel more comfortable contacting you with difficult questions. One day a recent graduate, with whom I communicated multiple times via school e-mail about other matters, sent me a private message through Facebook. She was about midway through her studies for the July bar exam, and she confessed that she had not taken any practice exams yet, and that she was afraid she might never start. I was able to work with her for the rest of the summer, and I wonder whether she would have reached out to me at all if we were not connected through Facebook.

Even if your students do not communicate with you directly, rest assured that helpful tips and encouragement shared via status updates - short statements that appear on all of your friends' homepages make an impact. (You can also link your status updates to a Twitter account, but that's a whole other article .) Once the bar exam was finished, a few graduates with whom I had not directly spoken all summer came back to campus just to say thank you. I also received this message: "Thank you so much for the positive thoughts and kind words of encouragement. I really needed it. It may sound funny, but it really helped having someone from the professional and academic world believe I could do it. Thank you for all your support!"

Although Facebook began as a social networking tool, its utility extends far beyond those boundaries today. You can use it to enhance your classes, help your students, and expand your program. If you have difficulty reaching your students, or if you are just looking for a new way to make yourself or your program even more accessible, the answer should be clear: find them on Facebook.

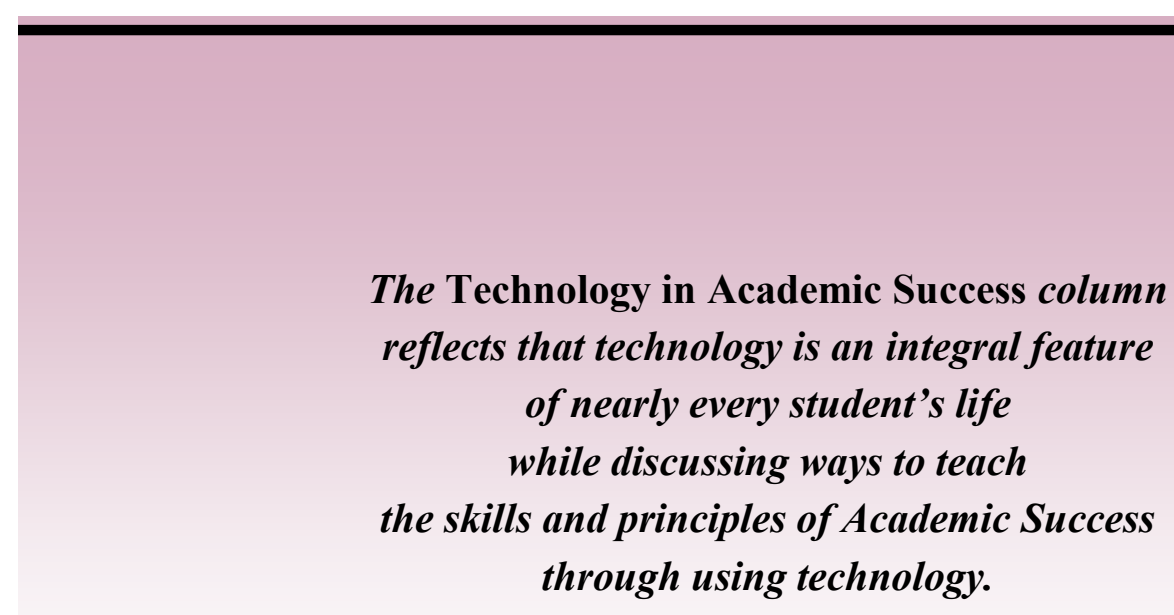

PAGE 23

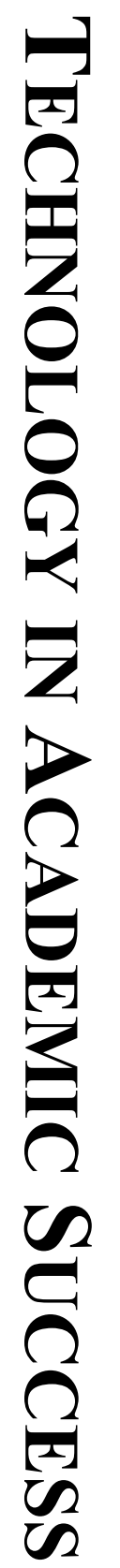

“Although Facebook

began as a social

networking tool, its

utility extends far

beyond those

boundaries today." 